\title{
Screening and selection of novel animal probiotics isolated from bovine chyme
}

\author{
Alper D. Ozkan • Diren Han • Ozgun C. O. Umu • Pinar Angun • \\ Berna Senturk • Oncay Yasa $\cdot$ Turgay Tekinay
}

Received: 9 July 2012 / Accepted: 5 December 2012 / Published online: 27 December 2012

(C) Springer-Verlag Berlin Heidelberg and the University of Milan 2012

\begin{abstract}
Probiotics, gut-colonizing microorganisms capable of conferring a number of health benefits to their hosts, are highly desirable as animal feed supplements. Members of the Gram-positive genus Bacillus are often utilized as probiotics, since endospores formed by those bacteria render them highly resistant to environmental extremes and therefore capable of surviving gastrointestinal tract conditions. In this study, 84 distinct bacterial colonies were obtained from bovine chyme and 29 isolates were determined as Bacillus species. These isolates were principally screened for their antimicrobial activity against a group of two Gram-positive and four Gram-negative bacteria, including known human and animal pathogens such as Salmonella enterica, Klebsiella pneumoniae, Pseudomonas aeruginosa, and Staphylococcus aureus. Seven strains displaying strong antimicrobial activity against the test cohort were further evaluated for other properties desirable from animal probiotics, including high spore-forming capacity and adhesiveness, resistance to $\mathrm{pH}$ extremes and ability to form biofilms. The isolates were found to resist simulated gastrointestinal conditions and most of the antibiotics tested. In addition, plasmid presence was checked and cytotoxicity tests were performed to evaluate the potential risks of antibiotic resistance transfer and unintended pathogenic effects on host, respectively. We propose that the bacterial isolates are suitable for use as animal probiotics.
\end{abstract}

Keywords Antimicrobial - Bacillus $\cdot$ Feed supplement . Isolation $\cdot$ Probiotics

A. D. Ozkan · D. Han · O. C. O. Umu • P. Angun • B. Senturk •

O. Yasa $\cdot$ T. Tekinay $(\triangle)$

Laboratory of Sustainable Technologies, UNAM,

Institute of Materials Science and Nanotechnology,

Bilkent University, 06800, Ankara, Turkey

e-mail: ttekinay@bilkent.edu.tr

\section{Introduction}

The widespread and intensive use of antibiotics for therapeutic purposes has led to a considerable increase in the number of antibiotic-resistant pathogenic strains, resulting in frequent occurrence of serious and hard-to-treat infections in both humans and livestock (Barbosa and Levy 2000; Barbosa et al. 2005; Chaiyawan et al. 2010). As such, there has been an increasing concern about non-therapeutic uses of antibiotics, ultimately culminating in bans of their use as animal feed additives. The European Parliament and the Council of the European Union have encouraged the development of alternative products to replace antibiotics as feed supplements for growth promotion (Santini et al. 2010; The European Parliament and the Council of the European Union 2003). Consequently, there is an ongoing search for replacement products capable of enhancing growth and preventing disease (Chaiyawan et al. 2010; Santini et al. 2010). An effective and safe alternative to antibiotic implementation is the use of probiotics, which protect the animal from pathogens by improving the microbial balance in the gastrointestinal tract to exclude potentially harmful bacteria (Chaiyawan et al. 2010; Modesto et al. 2009; Patterson and Burkholder 2003; Santini et al. 2010).

Probiotics are beneficial live microorganisms primarily including various species of bacteria and fungi (Duc et al. 2004; Lutful Kabir 2009). Probiotics influence the host organisms' health by maintaining the normal intestinal microbiota, preventing the growth of pathogenic microorganisms, promoting digestion and intake of feed, and inducing the immune system (Kim et al. 2009; Lutful Kabir 2009). As such, the use of probiotics on livestock enhances the growth of animals, improves efficiency of feed conversion, and decreases the rate of mortality (Kim et al. 2009; Lutful Kabir 2009). Probiotic microorganisms should ideally be non-pathogenic and nontoxic, improve growth of the host animal, and be stable and 
active during processing and storage. In addition, probiotics should be able to survive and continue their metabolic activities in gastrointestinal conditions and produce compounds that inhibit the growth of pathogenic microorganisms (Kim et al. 2009; Patterson and Burkholder 2003).

A number of bacterial species are currently used as probiotics, mostly in genera Bacillus, Bifidobacterium, Enterococcus, Escherichia, Lactobacillus, Lactococcus, and Streptococcus (Patterson and Burkholder 2003). Some yeast species, such as Saccharomyces cerevisiae, are also utilized as probiotics (Lutful Kabir 2009).

The most common probiotics used in humans are species of Lactobacillus and Bifidobacterium, while Bacillus, Enterococcus, and Saccharomyces species are frequently used in livestock (Patterson and Burkholder 2003). Bacillus species in particular are advantageous for use as probiotics, since members of this genus are spore-formers displaying high resistance to heat, chemicals, and other stress factors (Cartman et al. 2008; Chaiyawan et al. 2010; Nicholson et al. 2000; Setlow 2006., Bacillus spores can survive in harsh $\mathrm{pH}$ conditions of the gastric fluids (Cutting 2011) and reach the small intestine relatively unharmed, making them suitable for use as feed supplements. In addition, spores can be kept for a long time in desiccated form with little to no loss of viability, allowing for ease of transport (Duc et al. 2004; Mazza 1994). Bacillus subtilis, B. clausii, B. cereus, B. coagulans, and B. licheniformis are the Bacillus species most widely researched and used as animal probiotics (Cutting 2011).

In this study, novel bacterial strains were isolated from bovine chyme samples, and Bacillus strains obtained in this manner were characterized and screened for their potential to be used as animal probiotics. Criteria utilized for assessing probiotic capacity include survival in gastrointestinal tract (GIT) conditions, lack of toxicity and invasiveness, ability to adhere to the small intestine, and inhibition of pathogenic bacteria in the GIT by competitive exclusion or synthesis of antimicrobial compounds.

\section{Materials and methods}

Bacillus isolation and growth conditions

Microorganisms were isolated from chyme samples of eight male cattle between 2 and 4 years of age. The small intestine was removed as a whole and chyme samples were collected by squeezing the intestinal contents into sterile tubes. Isolation of the microorganisms was performed as described by Lalloo et al. (2007) with minor modifications. An amount of $1 \mathrm{~g}$ of chyme fluid from each sample was suspended in $3 \mathrm{ml}$ of $0.9 \% \mathrm{NaCl}$ solution and inoculated in $9 \mathrm{ml}$ of nutrient broth (NB). Samples were incubated at
$37{ }^{\circ} \mathrm{C}$ for $24 \mathrm{~h}$, followed by incubation at $45{ }^{\circ} \mathrm{C}$ for $10 \mathrm{~min}$ to initiate spore formation. Then, $50 \%(\mathrm{v} / \mathrm{v})$ ethanol was added to a volume of $20 \mathrm{ml}$ and the suspension was incubated at $20^{\circ} \mathrm{C}$ for $1 \mathrm{~h}$. Centrifugation was performed at $12,000 \mathrm{~g}$ for $30 \mathrm{~s}$, the supernatant was decanted, and pellets were incubated at $105{ }^{\circ} \mathrm{C}$ for $5 \mathrm{~min}$. Dry pellets were resuspended in $20 \mathrm{ml}$ of $0.9 \% \mathrm{NaCl}$ solution and serially diluted in ten-fold increments.

An amount of $150 \mu \mathrm{l}$ of each dilution was spread on MYP (Mannitol-Egg Yolk-Polymyxin) agar plates and incubated at $37{ }^{\circ} \mathrm{C}$ for $24 \mathrm{~h}$. Bacillus species were differentiated according to their ability to ferment mannitol or degrade lecithin, while polymyxin was utilized to inhibit the growth of Gram-negative bacteria. Single colonies with distinct morphologies were collected and transferred on Luria-Bertani (LB) agar plates. Cultures were incubated at $37{ }^{\circ} \mathrm{C}$ and $125 \mathrm{rpm}$ until visible colony formation, and stored at $4{ }^{\circ} \mathrm{C}$ to maintain viability. Cultures were maintained at $-80{ }^{\circ} \mathrm{C}$ in $30 \%$ glycerol for long-term storage.

\section{Antimicrobial activity}

Antimicrobial activity assay was adapted from the method described by Saravanakumari and Mani (2010). Overnight incubated cultures of the isolates were horizontally streaked on LB agar plates and incubated at $37{ }^{\circ} \mathrm{C}$ for $48 \mathrm{~h}$. After the incubation period, plates were exposed to chloroform vapor for $90 \mathrm{~min}$ for the inactivation of active cells. Plates were aerated for $20 \mathrm{~min}$ to completely remove residual chloroform by vaporization and plate covers were subsequently changed (Barbosa et al. 2005). Representative bacteria (Table 1) were then streaked vertically on the horizontally streaked colonies and plates were incubated at $37{ }^{\circ} \mathrm{C}$ for $24 \mathrm{~h}$. Inhibition on the bacterial growth line (Table 1) was assessed to evaluate the antimicrobial activity of isolates against each representative strain.

Table 1 Microorganisms used in the present study; all strains were obtained from RSHM (Refik Saydam National Type Culture Collection Laboratory, Ankara, Turkey)

\begin{tabular}{ll}
\hline Bacterial species & Strains \\
\hline Bacillus subtilis & ATCC 6633 (RSHM 03013) \\
Bacillus cereus & RSHM 709 \\
Staphylococcus aureus & ATCC 25923 \\
& (RSHM 96090/07035) \\
Escherichia coli & DH5 $\alpha$, RSHM 888 \\
Pseudomonas aeruginosa & ATCC 29212 (RSHM 03015) \\
Klebsiella pneumoniae & ATCC 10031 (RSHM 06017) \\
Salmonella enterica & ATCC 13311 (RSHM 4059, \\
& CIP 5858, NCTC 74)
\end{tabular}


Sporulation efficiency

Sporulation efficiencies of the isolates were measured as described by Barbosa et al. (2005). Isolates were inoculated $(0.1 \% \mathrm{v} / \mathrm{v})$ in Difco Sporulation Medium (DSM) and incubated at $125 \mathrm{rpm}$ and $37{ }^{\circ} \mathrm{C}$ for $24 \mathrm{~h}$. After $24 \mathrm{~h}$, serial dilutions were prepared in ten-fold increments and spread on LB agar plates before and after heat exposure at $80{ }^{\circ} \mathrm{C}$ for $20 \mathrm{~min}$. Plates were incubated at $37{ }^{\circ} \mathrm{C}$ overnight and colony-forming unit (CFU) numbers were counted; colony growth before and after heat exposure was compared to assess the sporulation capacities of the isolates.

\section{Spore formation}

Spores were harvested and purified to test the spore tolerance of each isolate to simulated gastric fluids and bile salts. Cultures were grown in $50 \mathrm{ml}$ DSM medium at $37{ }^{\circ} \mathrm{C}$, $250 \mathrm{rpm}$ for $24 \mathrm{~h}$ and centrifuged at $1,500 \mathrm{~g}$ for $5 \mathrm{~min}$ to refresh the medium of spores. Harvested spores were then inoculated in DSM medium and incubated at $37{ }^{\circ} \mathrm{C}$ and $250 \mathrm{rpm}$ for $48 \mathrm{~h}$. After the incubation period, spores were centrifuged at 5,000 $\mathrm{g}$ for $30 \mathrm{~min}$; spore pellets were washed with $20 \mathrm{ml}$ sterile distilled water and resuspended in $5 \mathrm{ml}$ sterile water. Spores of each isolate were stored at $4{ }^{\circ} \mathrm{C}$ for further use.

\section{Resistance to simulated gastric fluids}

Vegetative cells of the isolates were tested for survival capacity in simulated gastric fluids as described by Barbosa et al. (2005), Hong et al. (2008), and Patel et al. (2009) with minor modifications. Briefly, bacteria grown overnight were inoculated in LB broth $(\mathrm{pH}=2.0$, adjusted with $37 \% \mathrm{HCl})$ and incubated at $37{ }^{\circ} \mathrm{C}$ and $125 \mathrm{rpm}$ for $30 \mathrm{~min}$. Samples were then serially diluted, spread on LB agar plates and incubated at $37^{\circ} \mathrm{C}$ for $24 \mathrm{~h}$. Colonies were counted and compared with those of control cultures grown in unmodified LB broth.

Spore tolerance to simulated gastric fluids was also tested as described by Barbosa et al. (2005), Duc et al. (2004), Hong et al. (2008), and Patel et al. (2009). Approximately $10^{8}-10^{9}$ purified spores per $\mathrm{ml}$ were resuspended in $0.85 \%$ $\mathrm{NaCl}$ solution $(\mathrm{pH}=2$, adjusted with $37 \% \mathrm{HCl})$, incubated and spread on LB agar plates as described for vegetative cells. Spores resuspended in $0.85 \% \mathrm{NaCl}$ solution with no $\mathrm{pH}$ modification served as controls. Colonies were counted and compared with those of controls to assess the tolerance of spores to simulated gastric fluid conditions.

Bile salt tolerance

Bile salt tolerances of vegetative cells were tested as described by Barbosa et al. (2005). Overnight cultures of isolated bacteria were inoculated in fresh LB supplemented with $0.2 \%$ bile salts ( $50 \%$ cholic acid sodium salt, $50 \%$ deoxycholic acid sodium salt; Sigma-Aldrich, USA) and incubated at $37^{\circ} \mathrm{C}$ and $125 \mathrm{rpm}$. Bacteria inoculated in fresh LB not containing bile salts were incubated in parallel as controls. Aliquots were taken after $3 \mathrm{~h}$ of incubation, serially diluted and plated on LB agar; colonies were counted after incubation at $37^{\circ} \mathrm{C}$ for $24 \mathrm{~h}$.

Bile salt tolerances of spores were also assayed as described by Barbosa et al. (2005). Spores were purified as described by Henriques et al. (1995) and approximately $10^{8}-10^{9}$ purified spores per $\mathrm{ml}$ were resuspended in an isotonic buffer [Bott and Wilson salts: $1.24 \% \mathrm{~K}_{2} \mathrm{HPO}_{4}, 0.76 \%$ $\mathrm{H}_{2} \mathrm{PO}_{4}, 0.1 \%$ trisodium citrate, $\left.\left.0.6 \%\left(\mathrm{NH}_{4}\right)_{2} \mathrm{SO}_{4}, \mathrm{pH}=6.7\right)\right]$ containing $0.2 \%$ bile salts. Spores were incubated at $37{ }^{\circ} \mathrm{C}$ and $125 \mathrm{rpm}$, aliquots were taken at 0,1 , and $3 \mathrm{~h}$ and colony counts were performed to compare survival efficiencies. Spores resuspended in isotonic buffer not containing bile salts were incubated in parallel as controls.

\section{Biofilm formation}

Biofilm formation abilities of isolates were tested as described by Barbosa et al. (2005) with minor modifications. Instead of Sterlini-Mandelstam medium, a biofilm growth medium consisting of $\mathrm{LB}$ medium $(\mathrm{pH}=7)$ supplemented with $0.15 \mathrm{~mol} / 1$ ammonium sulfate, $0.1 \mathrm{~mol} / 1$ potassium phosphate, $0.034 \mathrm{~mol} / 1$ sodium citrate, $0.001 \mathrm{~mol} / 1 \mathrm{MgSO}_{4}$ and $0.1 \%$ glucose, (Hamon and Lazazzera 2001) was utilized in this study. Isolates were grown in this biofilm growth medium to exponential phase, transferred to $3 \mathrm{ml}$ of the same medium in a culture tube and incubated at $37^{\circ} \mathrm{C}$ without agitation to an optical density of $\sim 0.01$ at $600 \mathrm{~nm}$. An uninoculated culture tube and a culture tube freshly inoculated with exponential phase cells were utilized as controls. Tubes were rinsed with water and stained with a $1 \%$ crystal violet solution for $15 \mathrm{~min}$. Excess stain was then removed by washing. A ring of staining on the medium suggests that the bacteria are capable of forming biofilm.

Antibiotic susceptibility

Antibiotic resistances of the isolates were tested as described by Chaiyawan et al. (2010) and Santini et al. (2010) with modifications. Ampicillin, kanamycin, chloramphenicol, erythromycin, vancomycin, neomycin, ciprofloxacin, streptomycin, and gentamicin were the antibiotics tested. Two-fold serial dilutions of antibiotics were prepared in concentrations ranging between 1 and $256 \mu \mathrm{g} / \mathrm{ml}$. Next, $160 \mu \mathrm{l}$ of fresh LB broth, $20 \mu \mathrm{l}$ of appropriate dilutions of antibiotics, and $20 \mu \mathrm{l}$ of overnight grown isolates diluted to $10^{6} \mathrm{CFU} / \mathrm{ml}$ were added in each well of 96-well microtiter plates. Uninoculated LB broth and isolates inoculated in antibiotic- 
free LB broth were utilized as negative and positive controls, respectively. Plates were incubated at $37^{\circ} \mathrm{C}$ for $24 \mathrm{~h}$ and the minimum inhibitory concentrations of each antibiotic were determined by comparing sample turbidity at $620 \mathrm{~nm}$ to control wells.

\section{Plasmid DNA extraction and purification}

DNA minipreparation was performed to observe plasmid presence in isolates. Isolates were grown overnight at $37^{\circ}$ $\mathrm{C}$ and $250 \mathrm{rpm}$ in LB broth, confluent bacterial cultures were centrifuged at 12,000 $\mathrm{g}$ for $3 \mathrm{~min}$ to obtain cell pellets and plasmid DNA was extracted from the pellet of each isolate using QIAprep Spin Miniprep Kit (Qiagen, Germany). Gel electrophoresis was performed to determine whether the isolates carry plasmid DNA.

\section{Adhesion and invasion}

Adhesion and invasion assays of Bacillus isolates were performed as described by Rowan et al. $(2000,2001)$ with minor modifications. HT-29 cell monolayers were grown in DMEM supplemented with $10 \% \mathrm{FBS}$ and $1 \%$ penicillinstreptomycin at $37{ }^{\circ} \mathrm{C}$ in $5 \% \mathrm{CO}_{2}$ environment. Cells were seeded in 24-well plates containing approximately $3 \times 10^{5}$ cells per well and incubated overnight at $37{ }^{\circ} \mathrm{C}$ in $5 \% \mathrm{CO}_{2}$. Before adhesion and invasion assays, HT-29 cell monolayers were washed three times with DMEM and inoculated with $1 \mathrm{ml}$ of bacterial cultures previously washed with DMEM containing $10 \%$ FBS. 24-well plates were incubated at $37^{\circ}$ $\mathrm{C}$ in $5 \% \mathrm{CO}_{2}$ for $2 \mathrm{~h}$. After the incubation period, HT-29 cells were washed with DMEM to remove nonadherent bacteria. For the adhesion assay, HT-29 cells with adherent bacteria in $1 \mathrm{ml}$ of DMEM supplemented with $10 \%$ FBS were incubated for another $2 \mathrm{~h}$ at $37{ }^{\circ} \mathrm{C}$ in $5 \% \mathrm{CO}_{2}$. For the invasion assay, infected cells were incubated for $2 \mathrm{~h}$ in $1 \mathrm{ml}$ of DMEM containing $10 \% \mathrm{FBS}$ and $100 \mu \mathrm{g}$ of gentamicin per $\mathrm{ml}$ at $37{ }^{\circ} \mathrm{C}$ in $5 \% \mathrm{CO}_{2}$. Cells in both assay groups were then washed three times with DMEM and lysed with $1 \mathrm{ml}$ of $1 \%$ (v/v) Triton X-100 for 5 min at $37{ }^{\circ} \mathrm{C}$. Samples from lysed cells were serially diluted and spread on BHI agar plates for colony counting. Bacillus subtilis RSKK 03013 (ATCC 6633) and $B$. cereus RSKK709 were utilized as controls.

\section{Cell cytotoxicity}

Cytotoxic effects of isolates were tested as described by Rowan et al. (2000, 2001) and Hong et al. (2008) with modifications. An 3-(4,5-dimethylthiazol-2-yl)-2,5-diphenyl tetrazolium bromide (MTT) based in vitro toxicology assay kit (Sigma) was used to measure total cellular metabolic activity, the presence of which directly corresponds to the lack of cytotoxic effects. HT-29 cell monolayers were grown in
DMEM supplemented with $10 \%$ FBS and $1 \%$ penicillinstreptomycin at $37{ }^{\circ} \mathrm{C}$ in $5 \% \mathrm{CO}_{2}$ environment. The cells were then transferred to 96 -well plates with approximately $5 \times$ $10^{4}$ cells in each well and incubated overnight at $37^{\circ} \mathrm{C}$ in $5 \%$ $\mathrm{CO}_{2}$ atmosphere. Filter sterilized (by $0.2-\mu \mathrm{m}$ pore size membranes) supernatants of overnight grown bacteria (BHI, $37^{\circ} \mathrm{C}$, and $125 \mathrm{rpm}$ ) were added to test plates before and after heat treatment $\left(95^{\circ} \mathrm{C}, 10 \mathrm{~min}\right)$. Four replicates were done for the supernatant of each isolate, and $1 \%$ Triton X-100 (Sigma) and PBS were used as positive and negative controls, respectively. Cells inoculated with bacterial supernatant were incubated overnight at $37{ }^{\circ} \mathrm{C}$ in $5 \% \mathrm{CO}_{2}$. After the incubation period, the medium in each well was removed and $100 \mu$ l of DMEM supplemented with PBS containing $0.5 \%$ MTT was added to wells. Plates were incubated at $37{ }^{\circ} \mathrm{C}$ for $4 \mathrm{~h}$, after which $100 \mu \mathrm{l}$ of MTT solubilization solution (Sigma) was added to each well. The absorbance of the wells was measured at $570 \mathrm{~nm}$ by using a microplate reader (SpectraMax M5; Spectra Lab.). Background absorbance of well plates was also measured (at $690 \mathrm{~nm}$ ) and subtracted from $570 \mathrm{~nm}$ measurements. Toxicities of the supernatants to HT-29 cells were determined by using the equation (1-optical density of the test sample/optical density of the negative control) $\times 100$, where the resulting percentage represents the ratio of cellular respiration in the sample to respiration in an equal number of healthy cells (Rowan et al. 2001). Bacillus subtilis RSKK 03013 (ATCC 6633) and B. cereus RSKK709 were utilized as controls.

\section{Results}

Bacillus isolation and growth conditions

Chyme samples were collected from eight different male beef cattle for potential Bacillus probiotic isolation and 84 distinct isolates were obtained in total. Isolates were grown on MYP agar and 29 were found to be members of the genus Bacillus. All 29 isolates were observed to sporulate following heat exposure and inoculation in DSM broth. Light and scanning electron microscopy images were taken to confirm isolate morphology; all isolates were found to be bacilli (data not shown).

Antimicrobial activity

Antimicrobial effects of the selected Bacillus isolates were tested against different indicator strains, including four Gram-negative and two Gram-positive bacteria (Table 1). While all isolates displayed some antimicrobial activity, seven (STF4, STF8, STF9, STF10, STF15, STF25, and STF26) showed particularly strong inhibitory activity against the tested bacteria (Table 2). These seven isolates 
Table 2 Inhibitory activity of isolates as inferred by diameters of inhibition zones
Signs correspond to degrees of inhibitory effect on growth from - (no inhibition) to $+++; \pm$ reflects reduction in growth but not complete inhibition

\begin{tabular}{|c|c|c|c|c|c|c|}
\hline \multirow[t]{2}{*}{ Isolate } & \multicolumn{6}{|c|}{ Indicator strains } \\
\hline & S. aureus & P. aeruginosa & E. coli & B. subtilis & K. pneumoniae & S. enterica \\
\hline STF1 & - & - & - & + & - & - \\
\hline STF2 & - & - & - & - & - & - \\
\hline STF3 & - & - & - & - & - & - \\
\hline STF4 & ++ & ++ & ++ & - & ++ & - \\
\hline STF5 & + & \pm & - & \pm & \pm & - \\
\hline STF6 & \pm & \pm & - & + & \pm & \pm \\
\hline STF8 & ++ & \pm & + & +++ & - & \pm \\
\hline STF9 & + & - & - & ++ & - & - \\
\hline STF10 & + \pm & \pm & \pm & ++ & - & - \\
\hline STF11 & - & - & - & - & \pm & - \\
\hline STF12 & \pm & + & - & \pm & - & \pm \\
\hline STF13 & + & - & - & \pm & + \pm & \pm \\
\hline STF14 & + & - & - & - & + & \pm \\
\hline STF15 & +++ & \pm & \pm & \pm & - & - \\
\hline STF16 & \pm & - & - & \pm & - & \pm \\
\hline STF18 & \pm & - & - & - & - & \pm \\
\hline STF19 & \pm & - & - & \pm & \pm & \pm \\
\hline STF20 & - & - & + & \pm & \pm & \pm \\
\hline STF21 & \pm & + & - & - & - & - \\
\hline STF22 & \pm & + \pm & - & - & \pm & \pm \\
\hline STF23 & - & + & - & + & + \pm & - \\
\hline STF24 & - & + & + & - & - & - \\
\hline STF25 & \pm & \pm & + & +++ & - & - \\
\hline STF26 & +++ & \pm & +++ & + \pm & ++ \pm & ++ \\
\hline STF27 & + & - & - & + & - & - \\
\hline STF28 & - & \pm & - & \pm & + & - \\
\hline STF29 & \pm & \pm & - & \pm & - & \pm \\
\hline
\end{tabular}

were therefore chosen for further study, identified by $16 \mathrm{~S}$ rRNA sequencing (Table 3) and imaged by SEM to observe their cell morphologies. STF4, STF8, STF15, and STF26 were all effective in preventing the growth of $S$. aureus, while only STF4 showed inhibitory effect on $P$. aeruginosa. Further, while STF8, STF9, STF10, and STF25 all displayed a clear inhibition zone on the growth line of $B$. subtilis, only STF26 could effectively inhibit the growth of $S$. enterica. STF26 and STF4 also showed stronger antimicrobial activity on E. coli and K. pneumoniae compared to other isolates.

\section{Sporulation efficiency}

Sporulation efficiencies of the isolates STF4, STF8, STF9, STF10, STF15, STF25, and STF26 were tested by inducing spore formation in a sporulation medium and evaluating the number of colonies formed before and after heat exposure at $80{ }^{\circ} \mathrm{C}$. Colony numbers were compared and survival percentages were subsequently calculated from this data. The results are listed as percentages in Table 3. All isolates were spore-formers, although their sporulation efficiencies varied greatly. It is notable that while STF25 and STF26 had relatively low sporulation efficiencies, those isolates proliferated very rapidly in sporulation medium and could therefore have been resistant to the associated stresses. Sporulation rates for those isolates increased substantially after longer incubation times (48 and $60 \mathrm{~h}$ ), suggesting that STF25 and STF26 were disinclined to sporulate in the medium utilized for a certain time period. While other isolates also yielded higher sporulation rates after longer periods of incubation, those increases were not as drastic as the 1.5- and 1.6-fold increases seen in STF25 and STF26.

Resistance to simulated gastric fluids

Vegetative cells of the isolates STF4, STF8, STF9, STF10, STF15, STF25, and STF26 were tested for survival in simulated gastric fluids. All tested isolates were resistant to simulated gastric fluid conditions, although their survival 
Table 3 Identification and characterization of selected isolates

\begin{tabular}{|c|c|c|c|c|c|}
\hline Isolate & $\begin{array}{l}\text { 16S rRNA } \\
\text { sequence analysis } \\
\text { (Closest known species) }\end{array}$ & $\begin{array}{l}\text { Sporulation } \\
\text { efficiency }(\%)\end{array}$ & $\begin{array}{l}\text { Survival in } \\
\text { bile salt } \\
\text { (Vegetative form) }\end{array}$ & $\begin{array}{l}\text { Survival in simulated } \\
\text { gastric fluid } \\
\text { (Vegetative form) }\end{array}$ & Biofilm formation \\
\hline STF4 & Paenibacillus xylanexedens & 79.9 & + & + & - \\
\hline STF8 & Bacillus subtilis & 127.02 & +++ & ++++ & - \\
\hline STF9 & Bacillus subtilis & 22.75 & +++ & +++ & + \\
\hline STF10 & Bacillus licheniformis & 173.91 & +++ & ++ & + \\
\hline STF15 & Bacillus pumilus & 15.28 & + & +++++ & + \\
\hline STF25 & Bacillus licheniformis & 35.2 & + & ++++ & - \\
\hline STF26 & Bacillus pumilus & 36.7 & ++ & ++++ & + \\
\hline
\end{tabular}

Sporulation efficiency is given as the percentage of survivors

Plus signs under survival columns reflect the degrees of survival in simulated gastric fluid, + denoting the lowest survival and +++++ the highest. Plus signs under the biofilm formation column reflect presence of biofilm formation while minus signs denote absence of biofilm formation

rates were different (Table 3). Tolerance of purified spores of STF4, STF8, STF9, STF10, STF15, STF25, and STF26 to low $\mathrm{pH}$ condition of gastric fluids was also tested after $30 \mathrm{~min}$ and $1 \mathrm{~h}$ of incubation. After $30 \mathrm{~min}$, there was no reduction in the number of spores compared to controls. After $1 \mathrm{~h}$ incubation, there were 2-log reductions in the viability of STF15 and STF25 spores and no difference in STF4, STF8, STF9, STF10, and STF26 spores compared to controls.

\section{Bile salt tolerance}

Isolates were analyzed for their resistance to intestinal conditions by testing survival of both vegetative cells and spores in bile salts medium. Vegetative cells of all isolates were capable of surviving exposure to bile salts (Table 3). At 0 and $1 \mathrm{~h}$, no reduction was observed in the number of germinating spores of any isolate exposed to bile salts. After $3 \mathrm{~h}$ incubation in LB supplemented with bile salts, a 2-log reduction was observed in STF25; 1-log reductions were present in STF4, STF8, STF9, and STF10, a slight reduction was observed in STF26, and no reduction was found in STF15.

\section{Biofilm formation}

When grown in LB broth, isolates STF9, STF10, STF15, and STF26 formed highly viscous structures on the bottom of the tubes. After the biofilm assay, these isolates formed a notable ring of crystal violet, suggesting that the isolates are capable of forming biofilms (Table 3 ).

Antibiotic susceptibility and plasmid presence

Antibiotic selection and determination of resistance or sensitivity of isolates against chosen antibiotics were performed according to the microbiological breakpoints used by SCAN
(Scientific Committee on Animal Nutrition) (von Wright 2005). Minimum inhibitory concentration (MIC) values are displayed in Table 4. Of the isolates tested, all except STF4 were resistant to ampicillin, vancomycin and gentamicin; four isolates (STF8, STF9, STF15, and STF25) were resistant to kanamycin while another four (STF9, STF15, STF25, and STF26) were resistant to chloramphenicol. STF4 and STF8 were sensitive to erythromycin, whereas other isolates displayed resistance to this antibiotic. MIC values of STF4 and STF26 against neomycin were lower than the breakpoints mentioned in the SCAN report; therefore, they were considered as sensitive to neomycin. Three cultures (STF15, STF25, and STF26) showed resistance to ciprofloxacin and only STF26 exhibited low MIC values to streptomycin.

Since the isolates were resistant to many of the antibiotics tested, it is possible for one or more isolates to carry plasmids bearing antibiotic resistance genes, which may be then acquired by pathogenic organisms. As this outcome is highly undesirable, plasmid extraction and gel electrophoresis were performed to determine whether the observed resistances were transmissible. No plasmid presence was detected in the isolates STF4, STF8, STF9, STF10, STF15, and STF26; only STF25 displayed a faint band after gel electrophoresis (Fig. 1).

Adhesion and invasion

Abilities of Bacillus isolates to adhere to HT-29 cells were tested. We observed that all isolates tested could adhere to HT-29 cells (Table 5). STF9 could not grow in BHI broth; therefore, we could not perform the test for this isolate. STF4 showed the strongest adhesion with a percentage of $2.5 \%$ while STF15 showed the lowest with $0.002 \%$. Invasion properties of Bacillus isolates were also assayed as mentioned above. Assay results demonstrate that none of 
Table 4 Minimum inhibitory concentrations (MIC) of select antibiotics against isolates

$A, K, C H, E, V, N, C I P, S$, and $G$

refer to ampicillin, kanamycin, chloramphenicol, erytromycin, vancomycin, neomycin, ciprofloxacin, streptomycin, and gentamycin, respectively

\begin{tabular}{llllllllll} 
Isolate & \multicolumn{1}{l}{ Minimum Inhibitory Concentration (MIC) $\mu \mathrm{g} / \mathrm{ml}$} & & & & \\
\cline { 2 - 9 } & $\mathrm{A}$ & $\mathrm{K}$ & $\mathrm{CH}$ & $\mathrm{E}$ & $\mathrm{V}$ & $\mathrm{N}$ & $\mathrm{CIP}$ & $\mathrm{S}$ & $\mathrm{G}$ \\
\hline STF4 & $<1$ & $<1$ & $<1$ & $<1$ & $<1$ & 4 & $<1$ & 64 & $<1$ \\
STF8 & 16 & 64 & 8 & 2 & 4 & 64 & $<1$ & $>128$ & 16 \\
STF9 & 64 & 64 & 64 & 8 & 4 & 64 & $<1$ & 128 & 8 \\
STF10 & 128 & $<1$ & 8 & 4 & 8 & 64 & $<1$ & 128 & 16 \\
STF15 & 16 & 64 & 64 & 16 & 4 & 64 & 8 & $>128$ & 8 \\
STF25 & 128 & 64 & 64 & 128 & 128 & 128 & 16 & 128 & 16 \\
STF26 & 32 & 16 & 32 & 32 & 32 & 32 & 4 & 32 & 16 \\
\hline
\end{tabular}

that unmodified STF10 supernatant showed no toxicity to the HT-29 cell line, but the presence of a toxic material was observed after heating (Table 5). Bacillus subtilis ATCC 6633 supernatant displayed minor cytotoxicity both prior to and after heating, while $B$. cereus RSHM709 expressed both heat-labile and heat-stable toxins.

\section{Discussion}

Bacillus species are commonly used as probiotics, as these spore-forming bacteria can tolerate the harsh environmental conditions associated with the gastrointestinal tract. Bacillus species have been incorporated in commercial probiotic products, either alone or alongside consortia of other bacteria (Cutting 2011). Bactisubtil (B. cereus strain IP5832), Enterogermina (B. clausii), Biosubtyl Nha Trang (B. pumilus), and Bispan (B. polyfermenticus) are examples of commercially available Bacillus probiotics (Duc et al. 2004; Cutting 2011). Further, the production of natto, a fermented soybean product originating in Japan, involves the use of $B$. subtilis to facilitate the fermentation process, indicating that Bacillus species have been safely used in foodstuffs for a considerable period of time (Hong et al. 2008).

Bacillus species potentially suitable for use as probiotics were previously reported from the chicken and fish gastrointestinal tracts (Barbosa et al. 2005; Vijayabaskar and Somasundaram 2008). In a similar vein, we isolated Bacillus strains from bovine chyme and screened the isolates for probiotic potential, primarily utilizing antimicrobial activity as a measure of efficiency. Isolation of novel strains with high antimicrobial activity against pathogenic bacteria such as $S$. aureus, $P$. aeruginosa, S. enterica, and $K$. pneumoniae is highly desirable, as prevention of intestinal colonization by pathogenic bacteria is one of the principal ways by which probiotics bolster human and animal health. Other characteristics, such as the ability to survive the passage through the digestive tract and to successfully adhere to the intestinal mucosa, should also be considered in order to evaluate the capacity of a novel isolate as a potential probiotic.
Fig. 1 Agarose gel electrophoresis image of plasmid profile of isolates. $\mathbf{a}, \mathbf{b}, \mathbf{c}, \mathbf{d}, \mathbf{e}, \mathbf{f}$ and $\mathbf{g}$ represent STF4 (Paenibacillus xylanexedens), STF8 (Bacillus subtilis), STF9 (Bacillus subtilis), STF10 (Bacillus licheniformis), STF15 (Bacillus pumilus), STF25 (Bacillus licheniformis), and STF26 (Bacillus pumilus), respectively 
Table 5 Adhesion, invasion rates and cytotoxicity of Bacillus isolates against HT-29

\begin{tabular}{llllll}
\hline Isolate & Bacterial species & Adhesion (\%) & Invasion (\%) & \multicolumn{2}{l}{ Cytotoxicity (\%) } \\
\cline { 5 - 6 } & & & & Normal & Heat treated \\
\hline STF4 & Paenibacillus xylanexedens & 2.500 & 0 & 2.9 & 0 \\
STF8 & Bacillus subtilis & 0.010 & 0 & 95.2 & 68.6 \\
STF9 & Bacillus subtilis & - & - & - & - \\
STF10 & Bacillus licheniformis & 0.010 & 0 & 0 & 3.8 \\
STF15 & Bacillus pumilus & 0.002 & 0 & 11.6 & 7.5 \\
STF25 & Bacillus licheniformis & 0.100 & 0 & 7.8 & 0 \\
STF26 & Bacillus pumilus & 0.008 & 0 & 8.5 & 0 \\
ATCC 6633 & Bacillus subtilis & 0.466 & 0.050 & 4.5 & 2.7 \\
RSHM709 & Bacillus cereus & 0.126 & 0.338 & 81.8 & 14.5 \\
\hline
\end{tabular}

Spores of certain prospective Bacillus probiotics were found to be sensitive to the gastrointestinal tract (GIT) conditions (Duc et al. 2004). However, the ability of probiotic strains to survive in the GIT of the animal on which they are used as feed supplement is of great importance, as the probiotic bacteria cannot demonstrate their probiotic activities if they cannot colonize the gastrointestinal tract. Therefore, resistance of isolates to GIT conditions was tested with incubation in simulated gastric and intestinal fluids. Our results revealed that spores of the isolates were resistant to gastric fluid conditions after a 30-min incubation period, exhibiting $100 \%$ survival rates. However, survival rates of STF15 and STF25 spores displayed a marked decrease after $1 \mathrm{~h}$ incubation in simulated gastric fluids, while no reduction in viability was observed in the other 5 isolates. Similarly, spores of all isolates were found to be tolerant to simulated intestinal fluid conditions, with $100 \%$ survival rates after a 1 -h incubation period. However, survival rates decreased in spores of some isolates for longer incubation periods. Vegetative cells, on the other hand, were not as resistant as spores to stress conditions. This result is expected, as spores of the genus Bacillus have protective layers around the nucleoid in the spore core, making spores extremely resistant to adverse environmental conditions (Barbosa et al. 2005). Moreover, it has been reported that, once ingested, spores of Bacillus isolates could germinate in the GIT and display activity as vegetative cells in the host animal (Chaiyawan et al. 2010; Casula and Cutting 2002).

Our results demonstrate that STF9, STF10, STF15, and STF26 are capable of forming biofilm layers. Biofilm production is desired for prospective probiotics, since it allows the probiotic to remain longer in the GIT (Hong et al. 2008). Biofilm formation provides protection for probiotic bacteria against the harsh conditions of the GIT, supports spore formation, and prevents pathogenic bacteria from holding on to the GIT surface (Barbosa et al. 2005).

Antibiotic susceptibility is considered as one of the most important characteristics for probiotic bacteria, since the resistance genes could be transferred to pathogenic bacteria in the intestinal tract and thus contribute to the creation of multidrugresistant pathogens (Patel et al. 2009; Schwarz et al. 2001; Hong et al. 2005; Barbosa et al. 2005). This transfer mostly occurs by plasmid-borne resistance genes (Schwarz et al. 2001). In this study, seven isolates chosen after the initial screening were tested for antibiotic resistance against nine widely utilized antibiotics. Of those isolates, only STF4 had lower minimal inhibitory concentrations (MICs) than the breakpoints used by SCAN (von Wright 2005) and could be considered susceptible to the antibiotics tested. Other isolates (STF8, STF9, STF10, STF15, STF25, and STF26) were found to be resistant to at least one antibiotic tested. After the observation that most of the isolates displayed resistance to antibiotics, plasmid isolation and visualization was performed to determine whether this resistance is due to plasmid-borne resistance genes. If such genes are not integrated in genomic DNA and are instead carried on plasmids, they may be transferred to other bacteria in the environment and confer on them resistance to the same antibiotic. This constitutes a potential health hazard if the recipient bacteria are pathogenic, and the absence of plasmid DNA should therefore be confirmed for an antibiotic-resistant strain to be recommended as a prospective probiotic. As such, plasmid isolation was performed for all seven bacteria and the presence of plasmid was tested by performing gel electrophoresis. Our results suggest that all the samples tested, with the possible exception of STF25, carry potential antibiotic resistance genes in their genomic DNA and bear no risk of transferring them to other pathogenic or non-pathogenic bacteria that may be present in the environment (Hong et al. 2008). While it is possible that large, low-copy number plasmids have not been recovered by our isolation protocol, we find this possibility unlikely as cultures were grown to confluence several times in media lacking in antibiotics and, without the environmental stresses selecting for their presence, plasmids encoding antibiotic resistance genes would likely have been lost.

The ability to adhere to and colonize in the GIT is an important requirement for potential probiotics, as the capacity to adhere increases the mean time of bacteria in the GIT and 
allows greater periods of probiotic activity after oral introduction of the probiotic strain (Jacobsen et al. 1999; Saarela et al. 2000). Therefore, probiotic strains displaying stronger adhesion to the GIT are considered to better modify the normal intestinal microbiota, prevent the growth of pathogenic bacteria by competitive exclusion, and induce immune system compared to the non-adherent ones (Saarela et al. 2000; Patel et al. 2009). The HT-29 cell line is used as a model for the testing of adhesion of probiotic bacteria, as these cells differentiate into enterocytes (Saarela et al. 2000; Patel et al. 2009). Thus, we used the HT-29 colon carcinoma cell line for the assessment of cell adhesion by the prospective probiotic strains. In vitro adhesion assays suggest that all isolates except STF9 were able to partially adhere on the colon carcinoma cells, while STF4 had significantly higher adherence ability than the others. The adhesion rates observed were generally similar to the results obtained in other studies related to Bacillus adhesion and our own results on reference strains of B. subtilis and B. cereus (Hong et al. 2008; Rowan et al. 2001). Though our isolates had relatively low adhesion rates compared to previous records, STF4 again displayed higher adhesion than many strains in the literature.

Recent research suggests that members of Bacillus species might induce important systemic diseases such as septicemia, peritonitis, endocarditis, liver failure, and meningitis (Rowan et al. 2001). Therefore, invasion studies were conducted for our candidate probiotics. The test results suggest that none of the isolates invaded the HT-29 cells, displaying similar results to our B. subtilis reference strain. B. cereus RSHM709, however, was highly invasive. This result shows that our isolates are non-invasive and incapable of causing invasion-related diseases, though live animal tests should be conducted for further confirmation.

MTT assay was used for detection of toxic materials in bacterial supernatants. This assay was chosen as it has been determined to be more reliable and sensitive than other cell viability assays (European Commission 2000). In contrast to previous methods, which were based on visual evaluation of toxin-induced cell damage, MTT has the advantage of removing the subjective visual assessment from the assay. MTT is a yellow, water-soluble tetrazolium salt, which is cleaved in the mitochondria of metabolically active cells. In the presence of living cells, MTT solution displays a color change as the insoluble purple formazan is formed due to intramitochondrial metabolization of MTT (Rowan et al. 2001; Finlay et al. 1999; Beattie and Williams 1999; European Commission 2000). MTT assay is therefore highly sensitive for cellular respiration and suitable for assessing cell viability and cytotoxicity, since only living cells produce formazan reaction products (Beattie and Williams 1999; Finlay et al. 1999; Rowan et al. 2001). In this study, the cytotoxicity of cell-free supernatants was assessed by using MTT salts. STF8 had high levels of heatstable cytotoxic materials in its cell-free supernatant, while other isolates did not produce a significant level of toxic materials. STF10 in particular displayed $0 \%$ cytotoxicity. For STF4, STF25, and STF26, heat treatment of the culture supernatants eliminated toxicity to HT-29, suggesting that toxic materials produced by those isolates are protein-based. The relatively low toxicities of our isolates (bar STF8) is expected as our isolates generally belong to the $B$. subtilis group, which are generally considered safe for human and animal use. Our B. subtilis reference strain likewise displayed low cytotoxicity, while the $B$. cereus strain was highly toxic prior to heating and possessed a heat-stable toxin that allowed it to retain some toxicity after heat treatment.

In conclusion, Bacillus species were isolated from the GIT of bovine and assessed with regards to their potential capacity as probiotics. Among the isolates, STF4, STF10, STF15, and STF26 appeared to have the highest potential as probiotic candidates compared to other isolates, taking into account their antimicrobial effects, resistance to simulated gastrointestinal conditions, antibiotic susceptibility, colonization capacity, and lack of toxicity.

Acknowledgments We would like to thank Selma Bulut for her assistance in SEM imaging and cell culture studies and Zeynep Ergul Ulger for her help in cell culture maintenance and in carrying out the MTT assay protocol. This work is supported by grants from the State Planning Organization of Turkey (DPT).

\section{References}

Barbosa T, Levy S (2000) The impact of antibiotic use on resistance development and persistence. Drug Resist Update 3:303-311

Barbosa T, Serra C, La Ragione R, Woodward M, Henriques A (2005) Screening for Bacillus isolates in the broiler gastrointestinal tract. Appl Environ Microb 71:968-978

Beattie SH, Williams AG (1999) Detection of toxigenic strains of Bacillus cereus and other Bacillus spp. with an improved cytotoxicity assay. Lett Appl Microbiol 28:221-225

Cartman ST, La Ragione RM, Woodward MJ (2008) Bacillus subtilis spores germinate in the chicken gastrointestinal tract. Appl Environ Microb 74:5254-5258

Casula G, Cutting S (2002) Bacillus probiotics: spore germination in the gastrointestinal tract. Appl Environ Microb 68:2344-2352

Chaiyawan N, Tayeeteptaikul P, Wannissorn B, Ruengsomwong S, Klungsupya P, Buaban W, Itsaranuwat P (2010) Characterization and probiotic properties of Bacillus strains isolated from broiler. Thai J Vet Med 40:207-214

Cutting SM (2011) Bacillus probiotics. Food Microbiol 28:214-220

Duc L, Hong H, Barbosa T, Henriques A, Cutting S (2004) Characterization of Bacillus probiotics available for human use. Appl Environ Microb 70:2161-2171

European Commission (2000) Opinion of the scientific committee on animal nutrition on the safety of use of bacillus species in animal nutrition

Finlay WJ, Logan NA, Sutherland AD (1999) Semiautomated metabolic staining assay for Bacillus cereus emetic toxin. Appl Environ Microb 65:1811-1812

Hamon M, Lazazzera B (2001) The sporulation transcription factor Spo0A is required for biofilm development in Bacillus subtilis. Mol Microbiol 42:1199-1209 
Henriques A, Beall B, Roland K, Moran C (1995) Characterization of cotj, a sigma(e)-controlled operon affecting the polypeptide composition of the coat of Bacillus subtilis spores. J Bacteriol 177:3394-3406

Hong H, Duc L, Cutting S (2005) The use of bacterial spore formers as probiotics. FEMS Microbiol Rev 29:813-835

Hong H, Huang J, Khaneja R, Hiep L, Urdaci M, Cutting S (2008) The safety of Bacillus subtilis and Bacillus indicus as food probiotics. J Appl Microbiol 105:510-520

Jacobsen C, Nielsen V, Hayford A, Moller P, Michaelsen K, Paerregaard A, Sandstrom B, Tvede M, Jakobsen M (1999) Screening of probiotic activities of forty-seven strains of Lactobacillus spp. by in vitro techniques and evaluation of the colonization ability of five selected strains in humans. Appl Environ Microb 65:4949-4956

Kim K, Kim M, Kim D, Park Y, Kang J (2009) Characterization of Bacillus polyfermenticus KJS-2 as a probiotic. J Microbiol Biotechn 19:10131018

Lalloo R, Ramchuran S, Ramduth D, Gorgens J, Gardiner N (2007) Isolation and selection of Bacillus spp. as potential biological agents for enhancement of water quality in culture of ornamental fish. J Appl Microbiol 103:1471-1479

Lutful Kabir SM (2009) The role of probiotics in the poultry industry. Int J Mol Sci 10:3531-3546

Mazza P (1994) The use of Bacillus subtilis as an antidiarrhoeal microorganism. Boll Chim Farm 133:3-18

Modesto M, D'aimmo M, Stefanini I, Trevisi P, De Filippi S, Casini L, Mazzoni M, Bosi P, Biavati B (2009) A novel strategy to select Bifidobacterium strains and prebiotics as natural growth promoters in newly weaned pigs. Livest Sci 122:248-258

Nicholson WL, Munakata N, Horneck G, Melosh HJ, Setlow P (2000) Resistance of Bacillus endospores to extreme terrestrial and extraterrestrial environments. Microbiol Mol Biol Res 64:548-572

Patel A, Ahire J, Pawar S, Chaudhari B, Chincholkar S (2009) Comparative accounts of probiotic characteristics of Bacillus spp. isolated from food wastes. Food Res In 42:505-510
Patterson J, Burkholder K (2003) Application of prebiotics and probiotics in poultry production. Poultry Sci 82:627-631

Rowan N, Candlish A, Bubert A, Anderson J, Kramer K, Mclauchlin J (2000) Virulent rough filaments of Listeria monocytogenes from clinical and food samples secreting wild-type levels of cell-free p60 protein. J Clin Microbiol 38:2643-2648

Rowan NJ, Deans K, Anderson JG, Gemmell CG, Hunter IS, Chaithong T (2001) Putative virulence factor expression by clinical and food isolates of Bacillus spp. after growth in reconstituted infant milk formulae. Appl Environ Microb 67:3873-3881

Saarela M, Mogensen G, Fondén R, Mättö J, Mattila-Sandholm T (2000) Probiotic bacteria: safety, functional and technological properties. J Biotechnol 84:97-215

Santini C, Baffoni L, Gaggia F, Granata M, Gasbarri R, Di Gioia D, Biavati B (2010) Characterization of probiotic strains: an application as feed additives in poultry against Campylobacter jejuni. Int J Food Microbiol 104:S98-S108

Saravanakumari P, Mani K (2010) Structural characterization of a novel xylolipid biosurfactant from Lactococcus lactis and analysis of antibacterial activity against multi-drug resistant pathogens. Bioresource Technol 101:8851-8854

Schwarz S, Kehrenberg C, Walsh T (2001) Use of antimicrobial agents in veterinary medicine and food animal production. Int $\mathrm{J}$ Antimicrob Agric 17:431-437

Setlow P (2006) Spores of Bacillus subtilis: their resistance to and killing by radiation, heat and chemicals. J Appl Microbiol 101:514-525

The European Parliament and the Council of the European Union (2003) Regulation (EC) No 1831/2003 of the European Parliament and of the Council of 22 September 2003 on additives for use in animal nutrition

Vijayabaskar P, Somasundaram ST (2008) Isolation of bacteriocin producing lactic acid bacteria from fish gut and probiotic activity against common fresh water fish pathogen. Aeromonas hydrophilia. Biotechnol 7:124-128

Von Wright A (2005) Regulating the safety of probiotics - the European approach. Curr Pharm Design 11:17-23 